\title{
Under representation of morbidity from paediatric bicycle accidents by official statistics - a need for data collection in the accident and emergency department
}

\author{
P A Leonard, T F Beattie, D R Gorman
}

\begin{abstract}
Objectives-To determine the accuracy of currently available data on bicycle related injuries in children.

Setting-A paediatric accident and emergency $(\mathrm{A} \& \mathrm{E})$ department which annually treats approximately 30000 new patients under the age of 13 years.

Methods-Data on all attendances with bicycle related injuries over a four week period were compared with that currently available from police road traffic accident data (Stats 19) and the International Classification of Diseases, 10th revision, hospital discharge coding.

Results-Eighty six children attended the A\&E department. Only two bicycle related injuries were identified from Stats 19, and 10 from hospital discharge data.

Conclusion-Currently available official data do not give an accurate representation of the incidence of bicycle related injuries in children. If health promotion measures are to be assessed properly data collection needs to be improved.

(Injury Prevention 1999;5:303-304)
\end{abstract}

Keywords: bicycle; hospital statistics; surveillance; data collection

The Secretary of State for Scotland has recently announced a new transport action plan-to encourage the general public in Scotland to use alternative methods of transport to the motor car. ${ }^{1}$ The "school run" has been targeted in particular, with older children being encouraged to bicycle to school. In light of this a variety of health promotion measures have been proposed to attempt to minimise bicycle related injuries. These include promoting the use of bicycle helmets and provision of vehiclefree bicycle routes. ${ }^{1}$

It might be expected that these policies

Accident and Emergency Department. Royal Hospital for Sick Children, Edinburgh EH9 1LF, UK

P A Leonard

T F Beattie

Public Health Medicine, Lothian Health Board, Edinburgh

D R Gorman

Correspondence to: Paul Leonard, Senior House Officer
(2) Figures collated by the police detailing the number of bicycle related injuries that take place on public roads as part of the "Stats 19 " road traffic accident collection system. These statistical returns cover all accidents in which a vehicle is involved that occur on roads or footways and result in death or personal injury, if they become known to the police. (Details of Stats 19 data collection and analysis are published by the Scottish Office, ${ }^{3}$ and are also available on the internet at www.scotland.gov.uk.)

In order to determine how reliable a picture of bicycle related injuries can be gained from current data, we identified all bicycle related attendances at the accident and emergency (A\&E) department of the Royal Hospital for Sick Children (RHSC), Edinburgh. This department annually treats approximately 30000 new patients under the age of 13 years.

\section{Methods}

Over a four week period starting 22 August 1998, all children aged under 13 attending the A\&E department with bicycle related trauma were identified prospectively. Details of time and place of injury occurrence, and whether or not the police had been notified, were obtained from an interview. This interview was performed by the doctor or emergency nurse practitioner involved in the child's treatment. Data, including the eventual outcome (for example discharged or admitted), were collected on a standardised form. The triage nurse in the A\&E department highlighted all bicycle related presentations on the daily attendance sheet. This allowed identification and completion of missing or incomplete forms-either from the medical notes or from telephone interview of the carer.

Stats 19 figures for the Lothian and Borders region over the same period were prepared by the City of Edinburgh Council. This represents a larger geographical catchment area than that of our department. However it is not possible to match the areas more precisely. These data were then compared with both the number of patients reporting police involvement and the total number of attendances.

All hospital discharges for the RHSC with ICD-10 codings relating to bicycle injuries during the study period were identified by computer search. To identify children admitted during the study period but still an inpatient at the end of the study an additional two week period was also examined. Medical notes were then examined to determine reasons for any discrepancies with $\mathrm{A} \& \mathrm{E}$ data. 


\section{Results}

During the study period 86 children under the age of 13 with bicycle related injuries were seen in the $\mathrm{A} \& \mathrm{E}$ department. Our data identified that two reported police involvement at the time of attendance, although 65 had been on a "public road" (39 on the road itself, 26 on the pavement) at the time of their injury. Six children were cycling in their garden or yard, eight in a public park, three on car-free cycle routes, and four in other public places. The majority of children had minor injuries and were discharged, with 10 identified as having been admitted to hospital.

Stats 19 data identified two children aged less than 13 injured in bicycle accidents over the study period. It is not possible to be certain if these cases were those seen in the $A \& E$ department who reported police involvement as Stats 19 data do not include identifying patient details. When compared with A\&E data this represents only $3.1 \%$ (95\% confidence interval 2.45 to 3.75 ) of child bicycle injuries occurring on the road.

A total of 11 children were identified from ICD-10 codings as having been admitted to the hospital during the same period. However only eight of these corresponded with children that had been identified from $A \& E$ data.

The three children "missed" by A\&E data collection had not been admitted through the $\mathrm{A} \& \mathrm{E}$ department; two had been admitted electively for removal of $\mathrm{K}$ wires after bicycle related injuries before the study period but still generated bicycle related codings as a consequence of the mechanism of their original injury. One child with longstanding thrombocytopenia was admitted directly to the haematology ward for platelet transfusion after a minor fall from a bicycle. One of the two additional children identified by $A \& E$ data had been transferred directly from $A \& E$ to a tertiary referral centre at another hospital and therefore did not generate a discharge coding in our hospital. The second child had failed to be coded correctly as a bicycle related injury.

\section{Discussion}

Although the period of this study is relatively short it none the less identifies an important under representation of child bicycle injuries in currently available official data.

Previous work examining the accuracy of figures available for pedestrians involved in road accidents has shown an under reporting rate of $16 \%$ in police records when compared with $A \& E$ attendances. ${ }^{4}$ Our data suggest that this rate is significantly higher for child bicycle injuries. The police will only have details of injuries that were reported to them-many minor incidents, especially those involving child cyclists and no other vehicle, seem likely not to have been reported. This is supported by the fact that only two children reported police involvement at the time of their $\mathrm{A} \& \mathrm{E}$ attendance.

Inaccuracies in discharge codings in relation to all childhood accidents have been previously reported. ${ }^{5}$ Our data confirm that this source of error, while small, is still present. Explanations for this include:

(1) A child who requires several elective admissions after an injury generates a coding for each admission. These episodes are not yet readily linkable from routine data collection, although coding of admission type (emergency/ elective) is performed and could be used to overcome this error.

(2) Patients may be transferred directly from the A\&E department to a tertiary referral centre outside of the local area, thus generating their discharge code elsewhere.

(3) Inadequate documentation of the mechanism of injury may result in incorrect coding. Discharge codes are generated by retrospective review of medical notes. Failures to record accurately the mechanism of injury at the time of presentation will necessitate the use of more general "unspecified" codes.

However, even if all the inaccuracies in currently available official data were addressed, data on off-road injuries and patients treated exclusively in an A\&E setting would still be missing. In order to obtain this information, and similar data for other injuries, it is essential that data from $A \& E$ attendances are collected.

One way to do this would be to introduce a national computerised data collection system for all A\&E departments. Modified coding systems to allow recording of external cause of injury have already been proposed. ${ }^{6}$ The need for the simultaneous collection of standardised injury severity data has previously been identified $^{7}$ and could easily be included. Extension to cover minor injuries units and general practice attendances would increase the accuracy of figures further. Such computerised systems already exist in other countries, notably Canada $^{8}$ and Australia, ${ }^{9}$ and work done in Glasgow ${ }^{10}$ has shown that it is possible to set up a similar scheme in the UK

It would seem sensible for the government to introduce such a system before any further transport policy changes. This would allow a more accurate view of the extent of bicycle related injuries in children and any impact made by subsequent injury reduction policies and health promotion measures.

1 Scottish Office. Travel choices for Scotland: the Scottish integrated transport white paper. Edinburgh: HMSO, 1998.

2 Simpson AH, Mineiro J. Prevention of bicycle accidents. Injury 1992;23:171-3.

3 Scottish Office. Road accidents Scotland 1997. Edinburgh: HMSO, 1998.

4 Teanby D. Underreporting of pedestrian road accidents. BMf 1992;304:422.

5 Beattie TF. Accuracy of ICD-9 coding with regard to childhood accidents. Health Bull (Edinb) 1995;53:395-7.

6 Ribbeck BM, Runge JW, Thomason MH, et al. Injury surveillance: a method for recording $\mathrm{E}$ codes for injured emergency department patients. Ann Emerg Med 1992;21: $37-40$.

7 Beattie TF, Currie CE, Williams JM, et al. Measures of injury severity in childhood: a critical overview. Inj Prev 1998;4:228-31.

8 MacArthur C, Dougherty G, Pless IB. Reliability and validity of proxy respondent information about childhood injury: an assessment of a Canadian surveillance system. Am F Epidemiol 1997;145:834-41

9 Harrison J,Tyson D. Injury surveillance in Australia. Acta

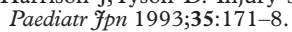

10 Stone DH, Doraiswamy NV. The Canadian Hospitals Injury Reporting and Prevention Program (CHIRPP) in the UK: a pilot study. Inj Prev 1996;2:47-51. 